\title{
COVID-19: An update of current knowledge (Review)
}

\author{
VAISHNAVI PANDEY ${ }^{1 *}$, AJAI SINGH $^{1 *}$, SALMA SIDDIQUI $^{2 *}$, ARCHANA RAIKWAR $^{1}$, \\ AMIT KUMAR GOND ${ }^{3}$, SABIR ALI $^{4}$, MANISH YADAV $^{4}$, AASHIMA DATTA $^{1}$ and ANAMIKA SINGH ${ }^{1}$ \\ Departments of ${ }^{1}$ Paediatric Orthopaedics, ${ }^{2}$ Biochemistry, ${ }^{3}$ Paediatrics \\ and ${ }^{4}$ Orthopaedic Surgery, King George's Medical University, Lucknow, Uttar Pradesh 226018, India
}

Received July 20, 2020; Accepted January 14, 2021

DOI: $10.3892 /$ wasj.2021.86

\begin{abstract}
There is a current public health issue threatening human health worldwide with the rapid spread of the novel coronavirus (2019-nCoV) or severe acute respiratory syndrome coronavirus-2 (SARS-CoV-2). The infection was reported to first originate in bats and subsequently spread to humans via yet unknown source animals in Wuhan, Hubei, China in December, 2019. Coronavirus disease 2019 (COVID-19) caused by extreme acute respiratory coronavirus-2 syndrome (SARS-CoV-2) is an unprecedented healthy global emergency. The outbreak of SARS-CoV-2 has once again revealed the vulnerabilities of global healthcare systems, the capacity of these systems to respond to an infectious threat, as well as the rate of infection and transmission across international borders. The present review article aimed to provide an update of the current knowledge regarding COVID-19 epidemiology, pathogenesis and transmission, as well as public health measures. The present review also emphasises the key learning points related to COVID-19 prevention and identifies the need to invest in healthcare systems, community-led defence systems, as well as the need for resilience and global health security.
\end{abstract}

\section{Contents}

1. Introduction

2. Epidemiology

3. COVID-19: Brief description and molecular structure

4. Transmission

5. Pathogenesis

6. Public health measures

7. Conclusion

Correspondence to: Professor Ajai Singh, Department Of Paediatric Orthopaedics, King George's Medical University, Lal Bhadur Shastri Bhawan, Nabiullah Road, RALC Campus, Lucknow, Uttar Pradesh 226018, India

E-mail: ajaipaedortho62@gmail.com

*Contributed equally

Key words: COVID-19, SARS CoV2, epidemiology, transmission, public health

\section{Introduction}

The coronavirus disease pandemic is not the first, and it certainly will not be the last to severely affect humanity. Previous pandemics have also attracted global attraction. The COVID-19 pandemic has created incentives for the development of an enhanced response system for potential pandemics. The next pandemic is considered inevitable. An approximate 1.7 million virus species circulate among wildlife and one third of these have the ability to cause human infections (1). With the upcoming cases and mortality rates, the elucidation of the reasons behind this increase in the number of cases is becoming a matter of concern. Cases were previously identified on the basis of travellers from foreign countries and the close contact of individuals with confirmed positive cases. At the time of the writing of the present review article, community transmission had already begun to occur in some countries, and it was estimated at that time that India had still not reached the level of community transmission. Thus, it is necessary to elucidate all possible reasons from which the spread of the disease can occur.

Studies are not only limited to determining molecular parameters, but also aim to determine the cause of transmission; public measures and the mode of transmission have also become a matter of concern of the current outbreak. There are a number of review articles available which have aimed at providing this information. From the 1960s, it was already known that coronaviruses are able to cause respiratory infections in humans; however, the epidemic potential of these viruses was only more deeply understood over the past 2 decades. The first cases of coronavirus infection were reported in 1960 as a cause for the common cold. Since that time, and up to 2002, 4 subtypes of coronaviruses were reported which are able to infect humans, namely $2 \alpha$ coronaviruses (229E and NL63) and $2 \beta$ coronaviruses (OC43 and HKU1); these subtypes have been shown to routinely produce non-complicated infections of the upper and/or lower respiratory tract (2).

Severe acute respiratory syndrome coronavirus-2 (SARS-CoV-2) has had a major impact on human health, and this has led numerous researchers to focus on the identification and development of effective treatment strategies with which to suppress the transmission of or ameliorate the disease. Even though there has recently been a very rapid and ample flow of publicly available scientific data on possible therapeutic solutions, to the best of our knowledge, no available studies to date 
have demonstrated indisputable methods which may be used for the effective clinical treatment of coronavirus disease 2019 (COVID-19). In order for this emerging disease to be effectively contained and mitigated, further and more in-depth knowledge regarding the virology, pathology and cross-species transmission of SARS-CoV-2 will have to be obtained. With the viral genome organization being determined at an unprecedented speed, the molecular pathogenesis of the disease and immunopathology related to protein products, modes of transmission, host cell entry mechanisms and kinetics, vesicular trafficking, protein and small molecule interactions, and biological and replication machinery mechanisms of action, are only beginning to be more fully understood (3).

SARS-CoV2 is composed of 2 types of molecules, namely RNA and proteins. RNA encodes for 27 viral proteins, of which 16 are non-structural proteins (nsps), and 11 are accessory and structural proteins. There are 4 major structural proteins: Nucleocapsid protein $(\mathrm{N})$, spike surface glycoprotein $(\mathrm{S})$, matrix protein $(\mathrm{M})$ and small envelope protein $(\mathrm{E})$. The $\mathrm{N}$-protein binds to viral RNA, encloses it in a capsid and assists RNA synthesis and folding during viral replication. It also modifies host responses, cell cycle and gene translation. In addition, following RNA replication, it guides the viral membrane proteins for viral assembly. The S-protein is essential for the attachment and fusion of the virus to host cells (4) (Fig. 1).

Basis of the methodology of the present review article. For the purposes of the present review, the authors searched articles with the key words 'COVID-19', 'CORONA VIRUS' and 'SARS-COV-2' in various search portals, such as PubMed, ClinicalKey, ERMED Consortium and Springer Nature journals. Overall, 222 review articles and 38 research articles were identified; however, following a thorough reading of these articles, only 28 out of these were shortlisted. Another 7-8 articles were also included following the recommendations of the corresponding author of the present study and following the reviewing process. The present review aimed to provide an updated of the current knowledge available on COVID-19 epidemiology, pathogenesis and transmission, as well as public health measures. Key learning points related to COVID-19 prevention are also emphasised together with the need to invest in healthcare systems and community-led defence systems, and the need for resilience and global health security.

\section{Epidemiology}

Coronaviruses are RNA-positive sensory viruses with spike-like projections, with diameters ranging from 60 to 140 $\mathrm{nm}$ on their top, thus providing a crown-like appearance under an electron microscope (5). It is known that 4 of the coronaviruses in humans, namely HKU1, NL63, 229E and OC43, usually contribute to minor respiratory disorders. Over the past 2 decades, 2 occurrences have resulted in severe disease arising from the cross-over of animal bedrock viruses into humans. The first such occurrence took place in 2002-2003, when the intermediate population of palm civet cats in Guangdong, China, passed a novel $\beta$-genera coronavirus, originating in bats, on to humans. In Hong Kong and China, 8,422 indi- viduals were infected by the virus, termed as an extreme acute respiratory disease coronavirus, which caused 916 deaths with a mortality rate of $11 \%$ (6). The second one occurred 2012; the Middle East respiratory syndrome coronavirus (MERS-CoV) appeared in bats as intermediate hosts of dromedical camels in Saudi Arabia and affected 2,494 individuals (7).

Due to a recently established $\beta$-coronavirus, an outbreak of pneumonia cases occurred in December, 2019 in Wuhan, China. At this time, in the capital Hubei, Wuhan, extreme cases of unexplained pneumonia among adults began to appear in local hospitals. The surveillance device (set up during SARS) was thus triggered, and patient respiratory samples were sent to etiological test laboratories. During the insurgence of the early cases, access to Huanan Seafood Wholesale Market and the trading of live animals were common. Subsequently, the World Health Organization (WHO) named the virus as (2019-nCoV) novel coronavirus on January 12, 2020. The COVID-19 was formally identified by the WHO, and the International Committee of Coronavirus Research Group (CSG) decided to name the novel SARS-CoV-2 coronavirus on February 11, 2020 (8). China notified the WHO on December 31, 2019 and closed down its market for aquatic food in Huanan on January 1, 2019. The virus was described on January 7, 2020 as a coronavirus with $>95 \%$ bat coronavirus homogeneity and $>70 \%$ SARS-CoV homogeneity. Following environmental tests, the Huanan seafood industry tested positive for the virus, thus suggesting that the infectious coronavirus initiated from Huanan, China. The numbers of infected patients subsequently began to markedly escalate; some of these newly infected individuals had no access to live animal markets, which indicated that the human-to-human spread of the virus had begun (9).

On January 11, 2020, the first fatal case of COVID-19 was identified. During the Chinese New Year, the huge influx of Chinese travellers accelerated the transmission of the epidemic. On January 20, 2020, transmission to patient healthcare professionals was identified. By January 23, 2020, lockdown and containment measures were place on the 11 million residents of Wuhan, inhibiting entries and exits from the city. This lockdown was rapidly extended and expanded to cities in the province of Hubei $(9,10)$. Cases of COVID-19 outside of China were recorded for those without a history of travelling to China, which suggested that in those countries, local human-to-human transmission had occurred (10). Airports in countries, such as India implemented screening protocols in order to detect symptomatic individuals returning from China. Although SARS-CoV-2 derived from bats, there is still uncertainty as to which intermediate species transmitted the virus to humans.

The virus was easily evident to asymptomatic individuals even before symptoms arose. Various countries, including India, who expatriated its citizens from Wuhan via special flights and those citizens who travelled back from China, tested all individuals for any symptoms. Even those individuals who were asymptomatic, were directed to undergo isolation for 14 days as a precaution. Cases however, have continued to be reported, and the viral spread has multiplied by 1.8 days in modelling studies (11).

From April 10, 2020 onwards, 9,129,146 confirmed cases of COVID-19 with 473,797 deaths in mainland China, 


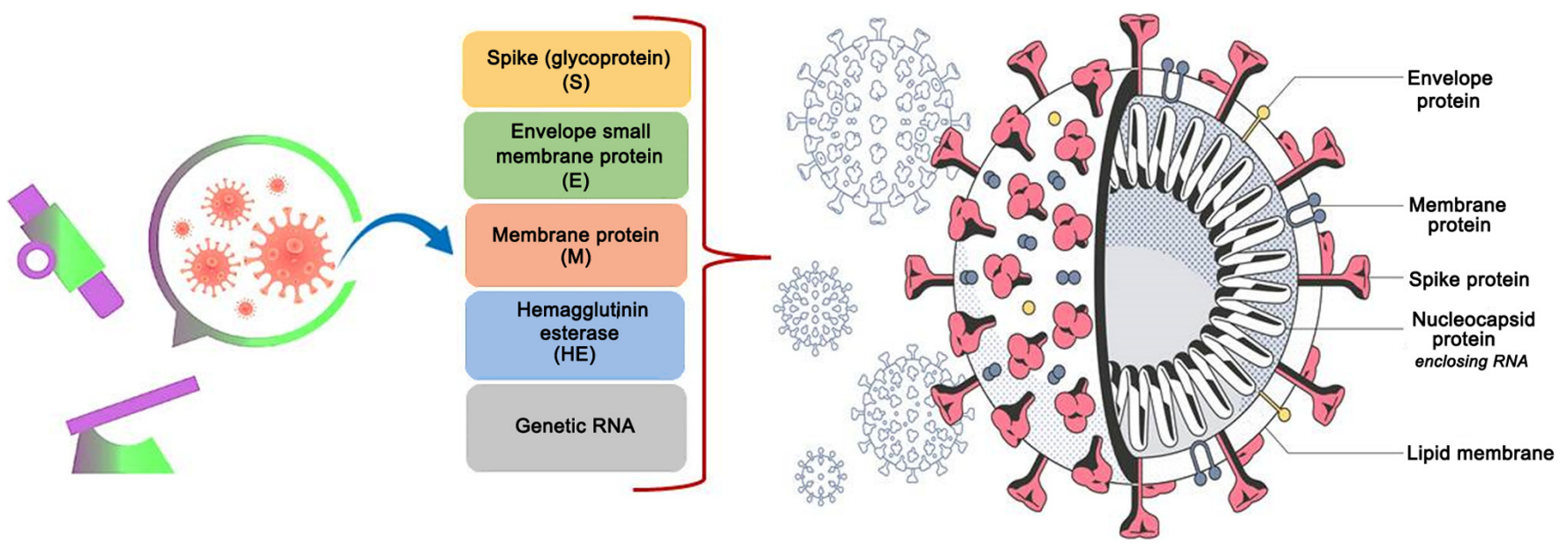

Figure 1. Structural diagram and components of COVID-19 virus.

USA, Italy, Russia, Spain, Germany, India, France, Iran, UK and Japan etc. were reported until June 24, 2020. Studies have predicted that the basic reproduction number (R0) of SARS-CoV-2 would be approximately 2 (12), or in fact additional (ranging from 1.4 to 6.5) (13) with familial clusters of pneumonia (14). Widespread outbreaks provide evidence of the continuously increasing human-to-human transmission of COVID-19. Although the number of new infected cases has recently decreased in China, the numbers in other countries, such as the USA, Italy, Korea and Iran have markedly increased, with $20 \%$ of cases being severely affected, $25 \%$ of cases recovered, and with $20-25 \%$ related deaths. At present, in $>215$ countries, the virus has spread within a brief time frame. The numbers of affected and COVID-19-related deaths are increasing every day. Further confirmed cases of infection were confirmed in China, followed by the UK, Canada, Italy, the Philippines, Spain, Sweden, Sri Lanka, Egypt, Singapore, Taiwan, Hong Kong, SAR, Korea, Japan, Malaysia, Vietnam, Australia, etc. (11).

\section{COVID-19: Brief description and molecular structure}

Identify of COVID-19. The coronavirus disease i.e., COVID-19 is a highly communicable disease caused due to the newly discovered coronavirus, which may induce flu-like symptoms, such as fever, dry cough (the 2 most frequent symptoms), weakness, nausea and nasal congestion, among others.

Molecular structure with a key virulent factor. There are $79.5 \%$ similarities in the genome of both COVID-19 and SARS-CoV (10) (Fig. 1). The spike protein plays a vital role in the entry of the virus into the native cell. Nsp1, Nsp3c and ORF7a are the 3 main coronavirus virulence factors synonymous with interfering with the innate immunity of the host and assisting in coronavirus immune escape. Recently, angiotensin-converting enzyme 2 (ACE2) was considered as a SARS-CoV-2 receptor, the infectious agent responsible for the disease, providing a critical link between immunity, inflammation, ACE2 and cardiovascular disease (15-17).

\section{Transmission}

As per the currently available information, the recently evolved coronavirus is predominately transmitted through aerosols, as well as through direct contact with infected surfaces. Therefore, for any specific prophylactic measures, both of these types of transmissions need to be considered (Fig. 2).

Transmission through direct contamination. Droplets are transmitted from an infected patient to healthy individuals. The entry of these aerosols can occur through the nose, ears, or eyes of an individual. The contamination can spread at a high level by means of coughing or sneezing in comparison with talking. A reasonable distance of 6 feet between individuals is advised in order to limit the distribution of such aerosols during clinical experiences, where necessary. COVID-19 can be sustained within aerosols for up to $3 \mathrm{~h}$ and thus, aerated rooms are always recommended $(18,19)$.

Transmission through indirect contamination. Of note, the attachment of SARS-CoV-2 on variable surfaces can vary; the virus can be detectable on stainless steel or plastic surfaces for up to 2-3 days, on copper for approximately $4 \mathrm{~h}$ and on cardboard surfaces for up to $24 \mathrm{~h}$ (20). Direct contact with such infected surfaces can also lead to infection. The regular and careful washing of hands with soap or disinfect gel is therefore advisable, particularly for medical staff. Likewise, all direct patient interaction points (doorknobs, furniture, pens, etc.) should also be regularly cleaned with disinfectant. In addition, the rubbing or touching of one's eyes, nose or mouth is not recommended and should be avoided. The use of tissue paper for the covering of one's mouth while coughing or sneezing, with the immediate disposal of the use tissue is also advisable. If a tissue is not available, sneezing and coughing into one's elbow is advised $(21,22)$.

Benefits of wearing masks to resist transmission. As the wearing of face masks poses a concern, a wide range of face masks (aerosol filters) are available with different 


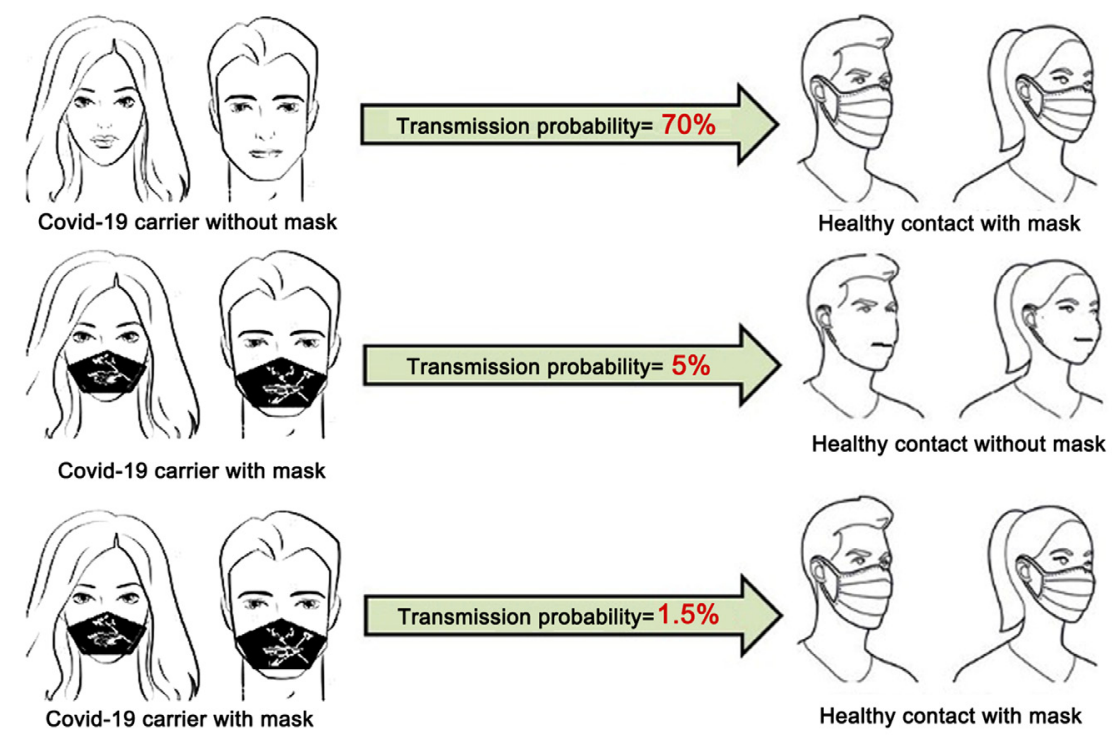

Figure 2. Importance of wearing of facemasks in the prevention of COVID-19 pathogenesis and transmission.

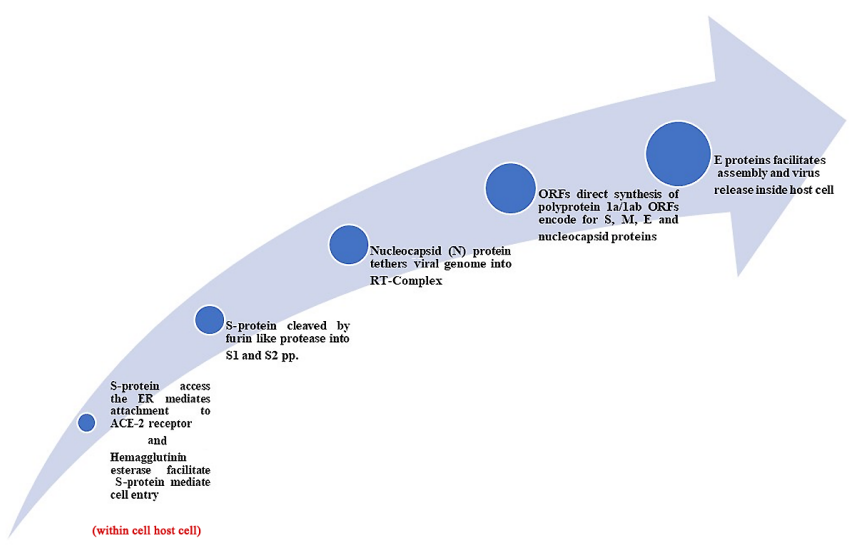

Figure 3. Simplified steps in the pathogenesis and replication cycle of COVID-19.

nomenclatures. As per the Centre for Disease Control (CDC) USA healthcare guidelines, an N95 face mask filters and does not allow $95 \%$ of 300 -nm-sized particles to through it. As the size of the coronavirus is approximately $100 \mathrm{~nm}$ (0.1 microns) (18), it could be assumed that it can easily pass through this mask. However, the fact is that the chance of the virus to pass through the filter (N95) is significantly low. This may be due to the Brownian motion (zig-zag movement) of suspended coronavirus in the air, which is not able to move linearly due to the substantial small size. Therefore, these viral particles often attach to the surface of the filters with relatively larger pore sizes. For this reason, N95 masks are only suggested for zones with a medium risk of infection; however, PPE kits are highly suggested for high-risk areas (19). The quality of the filter and airtight fitting around the facial surface (mouth and nose) are the most important factors to consider while selecting any N95 mask. However, as regards the repeated use of the face mask, this is not recommended, as the majority of these face masks cannot be easily sterilized and the coronavirus can remain alive on their respirator surface area for several hours and for up to
3 days if they have a plastic coating (20). Another matter of concern is the standard surgical face mask, which only offers $35 \%$ protection against aerosols; this not only due to the wider size of the holes in the material, but also due to the fact that these masks do not always fit securely and snugly around the neck, nose and mouth. This is due to the fact that surgical face masks were designed to mainly avoid infection of the surgical wound by aerosols during management from the surgical team, not to protect the whole surgical team from infection.

To date, at least to the best of our knowledge, there is no clinical study available which has compared the efficacy of N95 masks with surgical masks for protection against coronavirus. However, these masks were compared against the influenza virus, which is approximately the same particle size and with a similar mode of transmission (21). However, in any pandemic circumstances, masks are only the vital option for prevention. Marks help individuals by reducing the viral load and prevent viral shedding from symptomatic, as well as asymptomatic infected patients to the surrounding areas or to healthy individuals $(19,20)$. Similarly, glass or plastic shields should be used to avoid the contamination of aerosols through the eyes, particularly in infection-prone areas, such as hospitals (20).

\section{Pathogenesis}

Viral entry begins with attachment and entry into the cells, followed by genome translation, replication and transcription, and ending with assembly and release (23) (Figs. 3 and 4).

Viral entry into the cell. Coronavirus enters the body through the nose, mouth, eyes, ears and subsequently attaches to airway cells. The infection begins by the attachment of the viral spike to the host cell receptor, and the activation of the spike protein by cleaving it with host cell proteases. The protein cleavage creates the path for the entry of the virus into the host cell, either through endocytosis or viral envelope fusion with the host membrane (24). 
Clathrin-dependent endocytosis

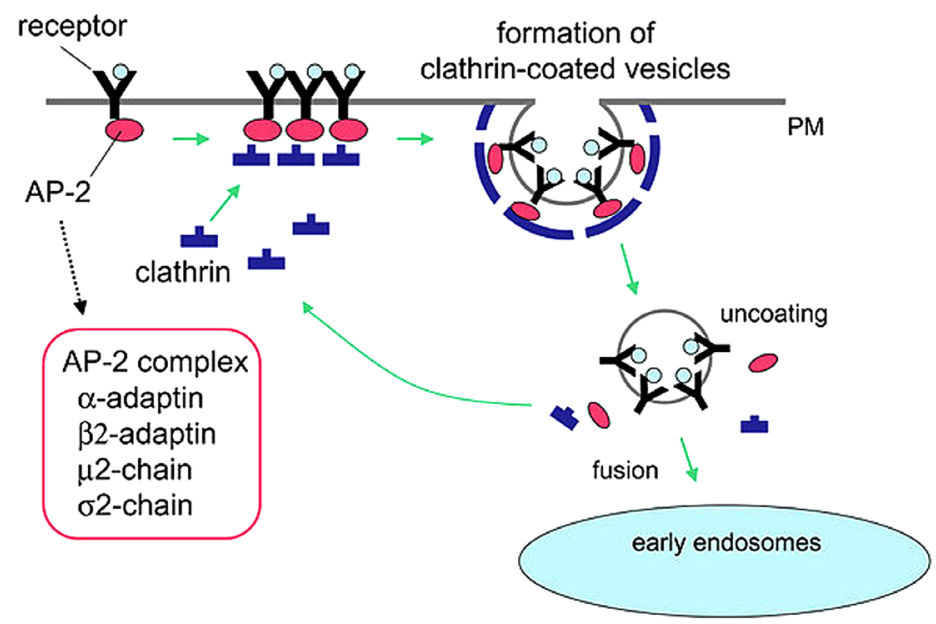

Figure 4. Mechanisms of clathrin-mediated endocytosis in cell invasion.

Endocytose-invasion. The S protein of coronavirus recognizes and binds to the receptor in order to invade the host cell through clathrin-mediated endocytosis mediated by the clathrin molecule (25). This protein forms a coated pit in the plasma membrane that bulges in the cell cytoplasm as a coated vesicle. These vesicles are involved in 2 major mechanisms: First, plasma membrane receptor-mediated endocytosis to the early endosome; and secondly in the Trans-Golgi Network (TGN) transport to endosomes (26). The adaptor protein (AP-2) is a multimeric protein that acts on the cell membrane to lead the transmembrane proteins to endocytosis. Clathrin and transmembrane proteins are turned into clathrin-coated vesicles (CCVs) and are transported to early endosomes (Fig. 4) (27,28).

Invasion via direct membrane fusion. Viral S-proteins are digested into $\mathrm{S} 1$ for receptor binding and $\mathrm{S} 2$ for membrane fusion subunits. The interaction between the $\mathrm{S} 1$ protein subunit and host receptor results in a conformational switch in the S2 protein subunit, which yields in the amalgamate of the viral envelope into the cell membrane, that triggers the release of nucleocapsid into the cytoplasm $(29,30)$.

Replication of the genome. Following viral uncoating, the replicative process begins with genome translation resulting synthesis of 2 large replicase polyproteins. In the end, 15 to 16 mature protein replicas are derived from 2 polyproteins (31).

Production of viral proteins by assembling new copies. In this virus, RNAs (mRNA) are functionally monocistronic; therefore, only the 5'-open reading frames (ORFs) are translated. However, some mRNAs, by using other mechanisms, such as internal ribosome entry, translate extra ORFs (29). The unusual size of the coronavirus genome creates an extensive set of RNAs which are connected to the number of non-structural proteins (nsps) being produced (32). The infected cell reads the RNA and begins generating proteins to hold the immune system at bay and assemble new copies of the virus. While the infection progresses, the cell's machinery begins producing new spikes and other proteins that form more copies of the coronavirus. Fresh copies of the virus are brought together and are transported to the outer edges of the cell (33).

Host-immune response. Following its attachment to the respiratory mucosa, the virus infects other cells, due to which a number of immune mechanisms occurs that produces a storm of cytokines in the body. In COVID-19-infected patients, natural (innate) immunity is required to kill the virus. In the infected host, plasma cytokines, chemokines, macrophages and hepatocyte growth factor (HGF) are detected (15). The pattern recognition receptors (PRRs) identify the viral RNAs as pathogenic molecular patterns (PAMPs) (34). These receptors are known for the identification of pathogenic RNA in the cytoplasm. This specific signalling hires adapters and interferon gene-stimulator protein to induce a cascade of molecules, which contain adapter molecule MyD88, that activates the transcriptional factor and IRF3 with IRF-I development and a variety of pro-inflammatory cytokines (35).

\section{Public health measures}

Public well-being and socio-economical interventions are initiatives or attempts by individuals, organizations, communities and national governments, and various international organizations to limit the spread of COVID-19. These interventions include individual and environmental actions, the identification and isolation of cases, the isolation and quarantine of infected individuals, and physical and social distancing measures. Up to the time of the writing of the present review article, international controls on transport were not imposed, and vaccinations and effective treatments were not yet available for COVID-19 $(15,32,33)$. General public measures include the adoption of flexible job structures, such as teleworking, online learning, crowd control and avoidance, the closure of non-essential amenities and facilities, the protection and safety of defenceless groups, certain restrictions on local or national travel and stay-at-home orders, as well as the co-ordinated 
Table I. Details of basic protective measures against the novel coronavirus.
Serial
Basic protective measures against
no. the novel coronavirus
Details

1 Regular washing of hands

$2 \quad$ Maintaining social distancing

3 Avoiding the touching of eyes, nose and mouth, and also maintaining respiratory hygiene

In the case of suffering from fatigue, cough or difficulty in breathing, medical treatment should be sought out immediately

Awareness is advised; the advice of healthcare providers should be followed
Washing of hands regularly with alcohol, or with water and soap Maintaining a distance (at least at least 1 meter or 3 feet) between you and individuals who are coughing or sneezing away Ensuring the practice of good respiratory hygiene, also protecting those around you. Protecting one's mouth or nose using the elbow or tissue, when coughing or sneezing. The used tissue should then be easily disposed of

Individuals who are unwell should remain at home. If an individual exhibits fatigue, cough or other symptoms, medical care should be sought, even via telephone. Municipal health department guidance should be adhered to

Individuals need to remain updated as to new COVID-19 developments. Individuals should follow the guidance given on how to protect oneself and others from COVID-19 infection restructuring of networks on wellbeing care and social services to protect hospitals. These procedures are used in combination with individual COVID-19 safety measures, including daily hand-washing and the etiquette for coughing (36).

Key features for avoiding the spreading of the disease. Steps for public health to avoid the spreading of the disease should be matched with adaptive approaches to promote community resilience and social ties, protect incomes and secure food supply. In general, due to social distancing, steps should also be introduced to establish personal and professional group links through virtual means and technology, including widely available means, such as through radio and telephones. Alongside all these steps, it is still essential to examine all suspect COVID-19 cases whenever possible, promptly isolate cases, identify the highest possible contacts, and ensure contact quarantine for the duration of the incubation period.

WHO has presented 4 stages of transmission for COVID-19. There are various countries, areas of locality with: i) no case being re-reported; ii) with sporadic conditions; iii) case cluster reporting; and iv) community transmission (37). Countries may wish to specify the steps to be taken at each point, periodically reviewing the situation. Essential services should remain operational, and socio-economic policies should enforce by governments to reduce the long-term economic effects, promote communal agility and allow for rapid recovery. Significantly, the aim is to achieve community transmission in clusters, intermittent cases, and then no cases at all, and consequently to begin lifting social measures slowly, as soon as it is deemed to do so. Guidance steps are being established for the lifting of these measures (15) (Table I).

Testing and tracing of COVID-19. As the signs and symptoms of COVID-19 infection are similar to a typical acute respiratory distress syndrome (ARDS), obtaining a travel history has been now considered for the screening out of patients suspected of being infected with COVID-19. Although some cases may be asymptomatic or even without fever, a final confirmation is made through a positive molecular test. The RT-PCR is usually performed to confirm the diagnosis of COVID-19; however, rapid ELISA-based test kits are also used for the mass screening of suspected cases. Sampling for molecular tests of COVID-19 is performed by obtaining throat swabs, nasopharyngeal swabs, sputum, bronchoalveolar lavage and endotracheal aspirates (9). However, in severe COVID-19 cases, the virus may also be detected in blood and stool samples. A normal chest X-ray at the early stages of infection can exhibit bilateral infiltrates. A computed tomography (CT) scan usually shows infiltrates, opacities, ground glass and sub segmental consolidation, and is considered to be much more sensitive and specific for the diagnosis of the disease. It is also helpful in the diagnosis of asymptomatic patients or suspected cases with negative molecular tests for COVID-19, which may further undergo repeated molecular tests (35).

Other hematologic parameters are usually non-specific. The white blood cell (WBC) count is usually normal or low; however, this is markedly decreased to $<1,000$ cells $/ \mathrm{mm}^{3}$ in severe COVID-19 cases. The erythrocyte sedimentation rate (ESR) and C-reactive protein (CRP) are usually increased. The serum procalcitonin level is usually normal, but seems to increase in bacterial co-infection. In the case of disease progression, the platelet count is usually normal or mildly low. The prothrombin time, alanine aminotransferase (ALT)/aspartate aminotransferase (AST), D-dimer, and creatinine, lactate dehydrogenase (LDH) and creatine phosphokinase (CPK) levels may be increased in severe COVID-19 cases (33).

\section{Conclusion}

Coronaviruses are RNA-positive sensory viruses with spike-like projections. In the present review, various aspect of COVID-19 transmission are described. COVID-19 exhibits $79.5 \%$ similarity with the genome of SARS-CoV. Infection is associated with flu-like symptoms and the ACE2 receptors play a critical role in the disease pathogenesis. Disease transmission can occur through direct and indirect contamination. 
Along with the testing/tracing procedure, hygiene, quarantine, physical and social distancing, the wearing of N95 masks are the other most effective measures to controlling the transmission of COVID-19. Masks help to prevent viral shedding from both symptomatic, as well as asymptomatic infected patients. However, the wearing of masks is not necessarily associated with complete protection from infection, as no such clinical evidence is yet available, at least to the best of our knowledge. Moreover, individuals with a compromised pulmonary system and extra pulmonary features along with febrile presentations and respiratory, pneumonia-like clinical conditions, require a physician's immediate attention. In addition, as elderly individuals are considered to have a poorer prognosis, closer attention should be paid to such cases.

\section{Acknowledgements}

Not applicable.

\section{Funding}

No funding was received.

\section{Availability of data and materials}

Not applicable.

\section{Authors' contributions}

VP, AjS and SS substantially contributed to the conceptualizing as well as the designing of the work. VP, AjS and SS also equally contributed in the finalizing the final version of the manuscript to be published. AR and AKG, have honestly contributed in drafting the manuscript, and also revising critically the mandatory intellectual recent data-based contents. SA was actively involved in the designing of work acquisition, and analysis of the research literature data presented in the review. MY, AD and AnS equally contributed to the conception and design of the study, as well as in all administrative aspects of the work. All authors read and approved the final manuscript and ensure that the questions related to the accuracy and integrity of the work will be appropriately investigated and resolved.

\section{Ethics approval and consent to participate}

Not applicable.

\section{Patient consent for publication}

Not applicable.

\section{Competing interests}

The authors declare that they have no competing interests.

\section{References}

1. Radford T: More avoidable pandemics await a heedless world. PreventionWeb, 2020. https://www.preventionweb. net/news/view/74677. Accessed November 11, 2020.
2. Docea AO, Tsatsakis A, Albulescu D, Cristea O, Zlatian O, Vinceti M, Moschos SA, Tsoukalas D, Goumenou M, Drakoulis N, et al: A new threat from an old enemy: Re-emergence of coronavirus (Review). Int J Mol Med 45: 1631-1643, 2020.

3. Nitulescu GM, Paunescu H, Moschos SA, Petrakis D, Nitulescu G, Ion GND, Spandidos DA, Nikolouzakis TK, Drakoulis $\mathrm{N}$ and Tsatsakis A: Comprehensive analysis of drugs to treat SARS-CoV-2 infection: Mechanistic insights into current COVID-19 therapies (Review). Int J Mol Med 46: 467-488, 2020.

4. Stancioiu F, Papadakis GZ, Kteniadakis S, Izotov BN, Coleman MD, Spandidos DA and Tsatsakis A: A dissection of SARS-CoV2 with clinical implications (Review). Int J Mol Med 46: 489-508, 2020.

5. Richman DD, Whitley RJ and Hayden FG: Clinical Virology. 4th edition. ASM Press, Washington, 2016.

6. Chan-Yeung M and Xu RH: SARS: Epidemiology. Respirology 8 (Suppl 1): S9-S14, 2003.

7. Omrani AS, Al-Tawfiq JA and Memish ZA: Middle East respiratory syndrome coronavirus (MERS-CoV): Animal to human interaction. Pathog Glob Health 109: 354-362, 2015.

8. Lu R, Zhao X, Li J, Niu P, Yang B, Wu H, Wang W, Song H, Huang B, Zhu N, et al: Genomic characterisation and epidemiology of 2019 novel coronavirus: Implications for virus origins and receptor binding. Lancet 395: 565-574, 2020.

9. Huang C, Wang Y, Li X, Ren L, Zhao J, Hu Y, Zhang L, Fan G, $\mathrm{Xu}$ J, Gu X, et al: Clinical features of patients infected with 2019 novel coronavirus in Wuhan, China. Lancet 395: 497-506, 2020.

10. Rothe C, Schunk M, Sothmann P, Bretzel G, Froeschl G, Wallrauch C, Zimmer T, Thiel V, Janke C, Guggemos W, et al: transmission of 2019-nCoV infection from an asymptomatic contact in Germany. N Engl J Med 382: 970-971, 2020.

11. Li Q, Guan X, Wu P, Wang X, Zhou L, Tong Y, Ren R, Leung KSM, Lau EHY, Wong JY, et al: Early transmission dynamics in Wuhan, China, of novel coronavirus-infected pneumonia. N Engl J Med 382: 1199-1207, 2020.

12. Riou J and Althaus CL: Pattern of early human-to-human transmission of Wuhan 2019 novel coronavirus $(2019-\mathrm{nCoV})$, December 2019 to January 2020. Euro Surveill 25: 2000058, 2020. Erratum in: Euro Surveill 25: 20200220c, 2020.

13. Liu Y, Gayle AA, Wilder-Smith A and Rocklöv J: The reproductive number of COVID-19 is higher compared to SARS coronavirus. J Travel Med 27: taaa021, 2020.

14. Chan JF, Yuan S, Kok KH, To KK, Chu H, Yang J, Xing F, Liu J, Yip CC, Poon RW, et al: A familial cluster of pneumonia associated with the 2019 novel coronavirus indicating person-to-person transmission: A study of a family cluster. Lancet 395: 514-523, 2020.

15. Guo YR, Cao QD, Hong ZS, Tan YY, Chen SD, Jin HJ, Tan KS, Wang DY and Yan Y: The origin, transmission and clinical therapies on coronavirus disease 2019 (COVID-19) outbreak - an update on the status. Mil Med Res 7: 11, 2020.

16. Li W, Moore MJ, Vasilieva N, Sui J, Wong SK, Berne MA, Somasundaran M, Sullivan JL, Luzuriaga K, Greenough TC, et al: Angiotensin-converting enzyme 2 is a functional receptor for the SARS coronavirus. Nature 426: 450-454, 2003.

17. Li MY, Li L, Zhang Y and Wang XS: Expression of the SARS-CoV-2 cell receptor gene ACE2 in a wide variety of human tissues. Infect Dis Poverty 9: 45, 2020.

18. Zhu N, Zhang D, Wang W, Li X, Yang B, Song J, Zhao X, Huang B, Shi W, Lu R, et al; China Novel Coronavirus Investigating and Research Team: A novel coronavirus from patients with pneumonia in China, 2019. N Engl J Med 382: 727-733, 2020

19. Bowen LE: Does that face mask really protect you? Appl Biosaf 15: 67-71, 2010

20. van Doremalen N, Bushmaker T, Morris DH, Holbrook MG Gamble A, Williamson BN, Tamin A, Harcourt JL, Thornburg NJ, Gerber SI, et al: Aerosol and surface stability of SARS-CoV-2 as compared with SARS-CoV-1. N Engl J Med 382: 1564-1567, 2020.

21. Smith JD, MacDougall CC, Johnstone J, Copes RA, Schwartz B and Garber GE: Effectiveness of N95 respirators versus surgical masks in protecting health care workers from acute respiratory infection: A systematic review and meta-analysis. CMAJ 188: 567-574, 2016.

22. National Institute for Health and Care Excellence (NICE): COVID-19 rapid guideline: critical care in adults. NICE, London, 2020. https://www.nice.org.uk/guidance/ng159. Accessed March 20,2020.

23. Belouzard S, Millet JK, Licitra BN and Whittaker GR: Mechanisms of coronavirus cell entry mediated by the viral spike protein. Viruses 4: 1011-1033, 2012. 
24. Simmons G, Zmora P, Gierer S, Heurich A and Pöhlmann S: Proteolytic activation of the SARS-coronavirus spike protein: Cutting enzymes at the cutting edge of antiviral research. Antiviral Res 100: 605-614, 2013.

25. Yang P and Wang X: COVID-19: A new challenge for human beings. Cell Mol Immunol 17: 555-557, 2020.

26. Robinson MS: Coats and vesicle budding. Trends Cell Biol 7: 99-102, 1997.

27. Glick BS and Malhotra V: The curious status of the Golgi apparatus. Cell 95: 883-889, 1998.

28. Gaidarov I, Santini F, Warren RA and Keen JH: Spatial control of coated-pit dynamics in living cells. Nat Cell Biol 1: 1-7, 1999.

29. Fung TS and Liu DX: Human Coronavirus: Host-Pathogen Interaction. Annu Rev Microbiol 73: 529-557, 2019.

30. Holmes KV, Tresnan DB and Zelus BD: Virus-receptor interactions in the enteric tract. Virus-receptor interactions. Adv Exp Med Biol 412: 125-133, 1997.

31. Brierley I and Dos Ramos FJ: Programmed ribosomal frameshifting in HIV-1 and the SARS-CoV. Virus Res 119: 29-42, 2006.

32. Leibowitz JL: Coronaviruses: Molecular and Cellular Biology. Emerg Infect Dis 14: 693-694, 2008
33. Tekes G, Hofmann-Lehmann R, Stallkamp I, Thiel V and Thiel HJ: Genome organization and reverse genetic analysis of a type I feline coronavirus. J Virol 82: 1851-1859, 2008.

34. Alexopoulou L, Holt AC, Medzhitov R and Flavell RA: Recognition of double-stranded RNA and activation of NF-kappaB by Toll-like receptor 3. Nature 413: 732-738, 2001.

35. Takeuchi $\mathrm{O}$ and Akira S: Innate immunity to virus infection. Immunol Rev 227: 75-86, 2009.

36. Rothan HA and Byrareddy SN: The epidemiology and pathogenesis of coronavirus disease (COVID-19) outbreak. J Autoimmun 109: 102433, 2020.

37. World Health Organization (WHO): Coronavirus disease 2019 (COVID-19) Situation Report - 72. https://www.who. $\mathrm{int} /$ docs/default-source/coronaviruse/situation-reports/20200401 -sitrep-72-covid-19.pdf?sfvrsn=3dd8971b_2. Accessed April 1, 2020.

This work is licensed under a Creative Commons Attribution-NonCommercial-NoDerivatives 4.0 International (CC BY-NC-ND 4.0) License. 